\title{
O perfil do pesquisador em educação ambiental: elementos para um estudo sobre a constituição de um campo de pesquisa em educação ambiental
}

\author{
Clarice Sumi Kawasaki ${ }^{1}$ \\ Mauricio dos Santos Matos e Marcelo Tadeu Motokane ${ }^{2}$
}

resumo: Com base na caracterização do perfil inicial do pesquisador em educação ambiental, em termos de sua formação e atuação no campo profissional e científico, buscou-se reconhecer elementos que pudessem servir de referenciais para o estudo sobre a constituição de um campo de pesquisa em educação ambiental (EA). Foram considerados, como sujeitos desta pesquisa, todos os participantes e demais envolvidos no I Encontro de Pesquisa em Educação Ambiental (I EPEA), evento caracterizado por sua especificidade na discussão da temática ambiental sob o foco da pesquisa em EA. Os dados necessários para a caracterização desse perfil foram obtidos por meio de fichas de inscrição preenchidas pelos participantes do evento e por meio dos currículos, disponíveis na plataforma Lattes do CNPq, de todos os sujeitos envolvidos no I EPEA, buscando reconhecer correspondências com os temas identificados nos trabalhos apresentados no evento. A análise dos dados obtidos na pesquisa foi realizada assumindo ambas as abordagens metodológicas, quantitativa e qualitativa, tendo como referenciais estudos sobre o perfil do educador ambiental. Como resultado dessa análise, foram identificados perfis variados de pesquisador em EA, resultantes de trajetórias não lineares, destacando-se a multiplicidade e a diversidade de sujeitos e contextos de formação e atuação. A

1 Docente da Faculdade de Filosofia, Ciências e Letras de Ribeirão Preto da USP e credenciada junto ao Programa de Pós-Graduação da Faculdade de Educação da USP. sumi@ffclrp.usp.br

2 Docente da Faculdade de Filosofia, Ciências e Letras de Ribeirão Preto da USP e credenciado junto ao Programa de Pós-Graduação Interunidades em Ensino de Ciências da USP.maumatos@ffclrp.usp.br e mtmotokane@ffclrp.usp.br 
partir da aplicação das categorias bourdieunianas, pôde ser reconhecido um campo de pesquisa em EA em formação, resultante da confluência de diferentes campos: o ambiental, o educacional e o científico. Outros contornos a respeito desse campo em formação foram também discutidos, apontando perspectivas para futuros estudos.

palavras-chave: perfil inicial, pesquisador em educação ambiental, formação e atuação

abstract: Based on the characterization of the first profile of the environmental education researcher, by means of his/her education and professional and scientific acting, we have sought to recognize some elements which might serve as references for studying the establishment of a research field in environmental education. We have considered as subjects of this research all people participating and involved in the First Research Meeting on Environmental Education (I EPEA, in Portuguese), an event marked by its specificity regarding the discussion of the environmental issue focusing the research in environmental eduacation. The necessary data for the characterization of these people were obtained through the application forms filled in by the event participants and through the curricula - available at CNPQ's Lattes database - of all people involved in the I EPEA. By using these data, we have sought to recognize some correspondences between them and the themes identified in the works presented at the event. The analysis of the data obtained in the research was made taking into consideration both methodological approaches, quantitative and qualitative ones, and having as references some studies about the environmental educator's profile. As a result of such analysis, we have identified diversified profiles related to the environmental education researcher, a consequence of non-linear paths, what brings special attention to the multiplicity and variety concerning the subjects and the educational and acting contexts. Based on the application of Bourdier's categories, it was possible to recognize a research field in environmental education being formed, a consequence of the confluency of different fields such as: the environmental, the educational and the scientific ones. Other configurations regarding this establishing field were also discussed, and so some perspectives were pointed out for incoming studies.

Key words: first profile, environmental education researcher, education and acting 


\section{Introdução}

Este trabalho visa traçar o perfil inicial do pesquisador em educação ambiental no Brasil, por meio de uma caracterização e análise dos participantes e demais envolvidos no I Encontro de Pesquisa em Educação Ambiental - I EPEA -, de forma a possibilitar o reconhecimento de elementos que possam servir de referenciais para o estudo sobre a constituição de um campo de pesquisa em educação ambiental (EA). As características desses sujeitos, priorizadas neste estudo, para o delineamento deste perfil, foram: distribuição geográfica, faixa etária, gênero, formação acadêmica, atuação profissional e atuação em pesquisa. Além disso, foram identificados os principais temas de pesquisa apresentados no evento, buscando compreender possíveis relações das diferentes temáticas de pesquisa com a formação acadêmica e com as instituições de origem dos autores dos trabalhos. Pesquisas anteriores de Kawasaki (2001) e de Carvalho (2001) foram utilizadas como referenciais de análise para este estudo.

A escolha do I EPEA para o delineamento deste perfil inicial justifica-se na medida em que esse encontro foi considerado um marco importante no cenário da pesquisa em EA, por constituir o primeiro evento do país com o objetivo específico de refletir sobre a produção da pesquisa na área, conferindo ao evento um caráter processual de construção de conhecimento e de consolidação da área de pesquisa em questão $^{3}$. Avanzi e Silva (2004) apontam, em seu texto de avaliação sobre o II EPEA, ocorrido em 2003, o pioneirismo da proposta de tais encontros, que vêm se consolidando por meio do esforço de pesquisadores consagrados na pesquisa em educação ambiental e de outros iniciantes na área.

3 A forte conexão entre os três encontros já realizados, com início em 2001, com um diagnóstico do "estado da arte" das pesquisas em educação ambiental, passando em seguida, em 2003, por uma discussão sobre as abordagens epistemológicas e metodológicas dessas pesquisas e, em 2005, avançando na direção da identificação das abordagens epistemológicas e metodológicas que têm sido utilizadas nas nossas práticas de pesquisa (Carvalho et. Al., 2001), veio conferir a esses encontros um caráter processual de construção de conhecimento e de consolidação da área de pesquisa em questão. 
Além de trazer contribuições para a caracterização do perfil do pesquisador em educação ambiental, este trabalho inicia a discussão sobre uma possível constituição de um campo - o da pesquisa em educação ambiental - com base no estudo dos sujeitos que o compõem. A teoria dos campos de Bourdieu (1983) e outros estudos que se apropriaram de suas categorias de análise, como os estudos sobre o campo da sociedade da informação de Almeida (2006), dos campos universitário francês e das Ciências Sociais de Garcia (1996) e da história do campo ambiental de Carvalho (2001), foram importantes referenciais para esta discussão.

\section{Metodologia}

Sujeitos da pesquisa:

Estabeleceu-se como o universo dos sujeitos desta pesquisa:

1) Os participantes brasileiros inscritos no evento, com ou sem autoria nos trabalhos apresentados;

2) Os autores de trabalhos apresentados, não inscritos no evento;

3) Os membros da comissão científica, inscritos ou não no evento.

Uma melhor visualização deste universo de sujeitos pode ser verificada na Figura 1. A ampliação do universo desta pesquisa para aqueles participantes que tiveram seus trabalhos recusados no evento, mas que estavam presentes, e para os autores de trabalhos aprovados, mesmo aqueles que não estiveram presentes, foi necessária por estes configurarem uma classe potencial de sujeitos na consolidação do campo da pesquisa em educação ambiental. A ampliação foi necessária também para diluir o viés comum num campo em consolidação, caracterizado pelo recorte dado na avaliação dos trabalhos, na qual há uma seleção prévia daqueles que serão aprovados ou não para apresentação no evento. Nesse sentido, foram também incluídos todos os membros da comissão científica por estes representarem a autoridade científica que define o perfil dos trabalhos. 


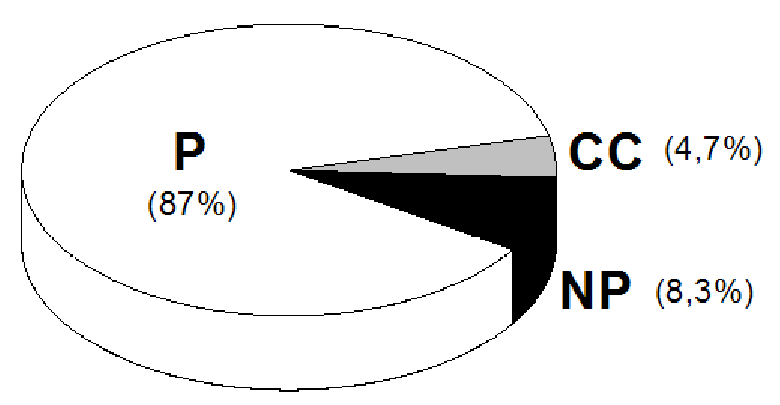

Figura 1. Esquema ilustrando o universo de sujeitos considerados nesta pesquisa: todos os participantes brasileiros inscritos no evento, com ou sem autoria nos trabalhos apresentados $(\mathrm{P})$; todos os membros da comissão científica, inscritos ou não no evento (CC); e todos os autores de trabalhos apresentados, não inscritos no evento (NP).

As informações necessárias para a caracterização dos sujeitos considerados nesta pesquisa foram obtidas a partir dos formulários de inscrição preenchidos pelos participantes, como também a partir da análise dos currículos - obtidos na plataforma Lattes do CNPq - dos autores de trabalhos e membros da comissão científica que não participaram do evento.

Identificação dos temas de pesquisa e suas relações com os pesquisadores e suas instituições de origem:

Neste estudo, foram analisados 78 resumos de trabalhos aprovados para apresentação no evento, dentre os 142 submetidos. Nessa seleção de trabalhos, a comissão científica estabeleceu, como critério inicial, que somente as pesquisa científicas, na forma de relatos de pesquisa ou ensaios críticos, seriam aprovadas, ao passo que os relatos de experiências só poderiam ser aprovados se estivessem no formato de uma pesquisa científica. A avaliação sobre a pertinência, relevância e clareza dos aspectos que configuram uma pesquisa científica foi realizada numa segunda etapa. A identificação dos temas de pesquisa foi realizada com base na análise dos resumos desses trabalhos de pesquisa, que se encontram impressos no Caderno de Resumos do evento. Sabe-se que a utilização de resumos como 
documentos de referência para a análise da natureza dos trabalhos impõe uma limitação intrínseca para a identificação e caracterização das pesquisas desenvolvidas. Desse modo, a análise realizada nesta pesquisa limitou-se apenas à identificação dos diferentes temas abordados nos trabalhos, sem aprofundar os demais aspectos dos mesmos. Para a caracterização dos diferentes temas abordados nos resumos, foram utilizadas categorias oriundas da área educacional, acrescidas de categorias construídas historicamente na área ambiental e na educação ambiental. Em relação a esses temas, identificou-se ainda a freqüência de trabalhos por tema (Tabela 1). Além disso, foram identificadas as instituições de origem dos pesquisadores que apresentaram trabalhos no evento, categorizando-as pela natureza das mesmas (instituições universitárias/não universitárias; públicas/privadas; federais/estaduais/municipais; governamentais/não governamentais ) em relação a dois aspectos: o número de autorias (Tabela 2) e o número de autorias separado pelos oito principais temas identificados nos trabalhos deste evento (Tabela 3). A intenção destas tabelas foi cruzar dados para buscar possíveis relações entre as temáticas de pesquisa desenvolvidas, pesquisadores e suas instituições de origem. Entende-se por autoria a participação de um autor em cada um dos trabalhos apresentados no evento.

A análise do perfil do pesquisador em EA e a constituição do campo da pesquisa em EA:

A partir dos dados de origem geográfica (Figura 2), gênero e faixa etária (Figura 3), formação acadêmica (Figura 4), atuação profissional (Figura 5) e atuação em pesquisa dos sujeitos (Figura 6), buscou-se traçar o perfil inicial do pesquisador em EA. O cruzamento desses dados, tais como, a formação acadêmica, a atuação profissional e a atuação na pesquisa, permitiu destacar tendências variadas na trajetória desses sujeitos, que auxiliaram na configuração do perfil. Estudos sobre o perfil do educador ambiental, de Kawasaki (2001) e de Carvalho (2001), foram tomados como referenciais para análise dos dados obtidos. Somando esses resultados àqueles encontrados no 
estudo sobre a identificação dos principais temas de pesquisa e suas relações com os pesquisadores e suas instituições de origem, buscou-se delinear alguns contornos a respeito desse campo científico em formação. Para os estudos sobre a constituição de um campo de pesquisa em EA, foram utilizadas as categorias bourdieunianas, bem como estudos que aplicaram essas categorias na configuração de outros campos - acadêmico, das ciências da informação e ambiental.

\section{a. Caracterização geral dos sujeitos da pesquisa}

1. A origem por Estados e regiões: abrangência geográfica.

Verifica-se uma predominância da Região Sudeste $(84,1 \%)$, sobretudo do Estado de São Paulo (74,1\% do total), seguido do Estado do Rio de Janeiro (4,7\%). Todavia, há uma presença significativa de Estados da Região Sul (7,6\%), com os Estados de Santa Catarina, Paraná e Rio Grande do Sul sobrepujando os Estados de Minas Gerais $(2,0 \%)$ e Espírito Santo (0,2\%), que fazem parte da Região Sudeste.
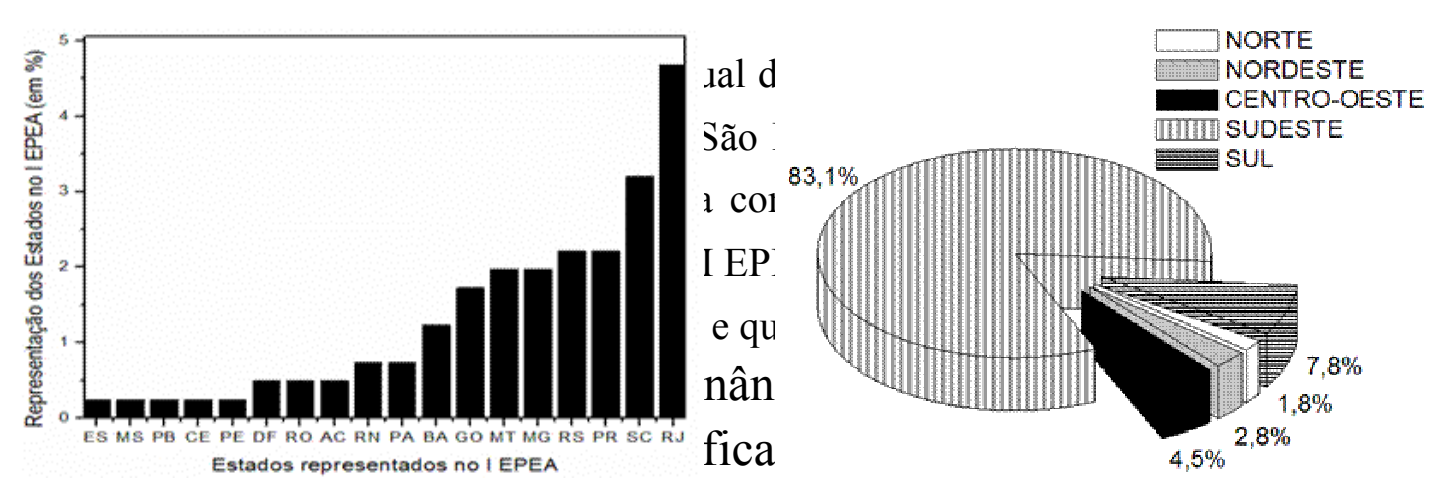

Sudeste no evento -, é possível afirmar que o evento teve uma abrangência nacional, já que contou com a presença de 19 Estados e de todas as regiões brasileiras.

2. Gênero e faixa etária:

Quanto ao gênero (Figura 3a), há uma predominância de mulheres (66\%) em relação aos homens (34\%). Quanto à faixa etária (Figura $3 b$ ), foi identificado um público com uma média de idade de 
34 anos, havendo uma maior concentração desse público na faixa de 20 a 30 anos. Trata-se de um público jovem, considerando que o evento refere-se a uma comunidade de pesquisadores.

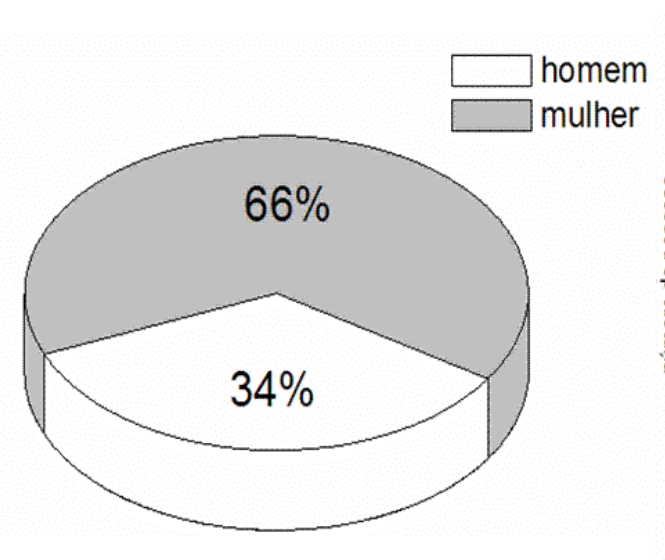

(a)

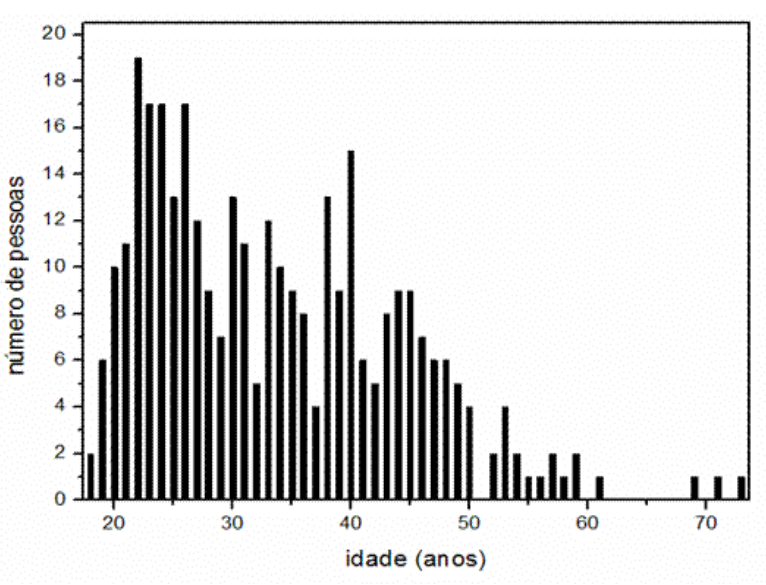

(b)

Figura 3. a) Porcentagem de homens e de mulheres e b) Distribuição etária, tomando-se $82 \%$ do total de sujeitos considerados nesta pesquisa e que declararam a idade.

3. Formação acadêmica:

Verifica-se na Figura 4a que a formação acadêmica dos sujeitos considerados nesta pesquisa abrange todas as áreas do conhecimento com uma predominância da formação inicial na área das Ciências Biológicas (56\%), com uma composição expressiva de biólogos $(45,8 \%)$, ecólogos $(4,6 \%)$ e profissionais com formação em licenciatura em ciências $(4,3 \%)$. Verifica-se também um significativo percentual de pessoas formadas nas áreas das Ciências Humanas (22\%) e das Ciências Agrárias (8,1\%), destacando-se a presença expressiva de pedagogos $(6,8 \%)$ e de geógrafos $(8,9 \%)$, em cada uma dessas áreas, respectivamente. 


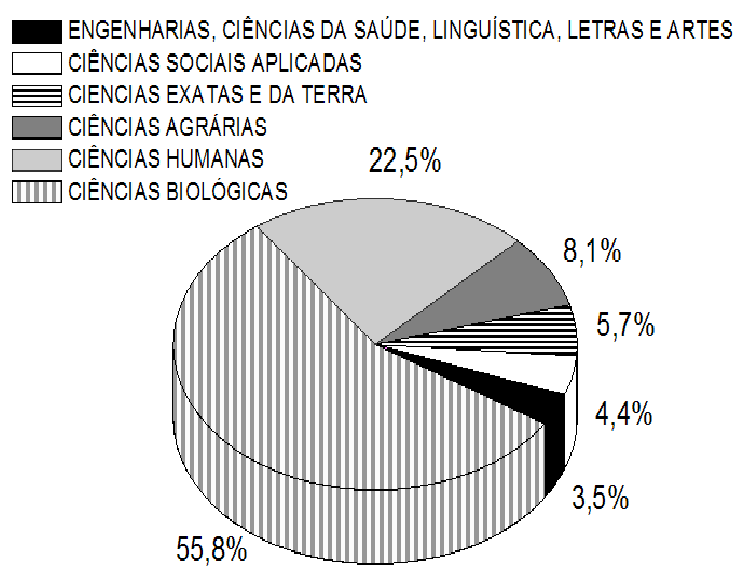

(a)

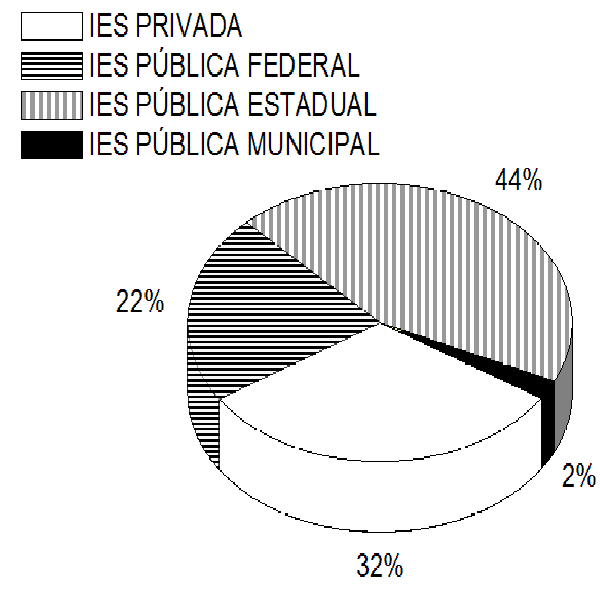

(b)

Figura 4. a) Área de formação inicial dos sujeitos considerados na pesquisa. Dados relativos a $85,5 \%$ dos sujeitos que declararam a sua formação inicial. Nesse cálculo, foram também considerados cursos em andamento; b) Categoria administrativa da Instituição de Ensino Superior onde os sujeitos desenvolveram sua formação inicial.

Apesar da predominância dos cursos da área das Ciências Biológicas, Agrárias e Humanas, verifica-se uma dispersão e uma multiplicidade de cursos oriundos das áreas de Ciências Exatas e da Terra, Ciências Sociais Aplicadas, Engenharias, Ciências da Saúde, Lingüística, Letras e Artes, configurando-se uma composição multidisciplinar.

Possivelmente, as ciências da natureza são áreas preponderantes porque correspondem àquelas que, mais tradicionalmente, estão relacionadas aos campos ambiental e da educação ambiental. Segundo Trivelato (2001), entender e apreciar as inter-relações dos seres humanos e seus meios biofísicos já era, de certa forma, objeto da Ecologia e das Ciências Naturais e, por isso, as disciplinas Ciências e Biologia eram os caminhos preferenciais que levaram a educação ambiental para a escola. De fato, essa concepção de cunho naturalista é ainda predominante nos vários contextos educacionais, embora a entrada de outras áreas no campo ambiental demonstre uma transformação na própria concepção de meio ambiente, 
que passa a incorporar não somente os aspectos naturais, mas também os sócio-ambientais.

Observa-se na Figura 4b que a formação inicial ocorre, em sua maioria, em Instituições de Ensino Superior (IES) públicas, havendo uma grande concentração no Estado de São Paulo, locus da formação inicial da maior parte dos sujeitos considerados nesta pesquisa. A formação inicial em IES privadas é significativa, superando a formação em IES federais.

\section{Atuação profissional:}

Quanto às profissões, há o predomínio de profissionais da educação $(74,4 \%)$, sendo estes professores universitários $(48,3 \%)$, professores da educação básica, educação profissional e profissionais da administração e coordenação escolar (26,1\%). Verifica-se ainda a presença de educadores ambientais e funcionários que atuam em entidades da área ambiental $(17,1 \%)$, pesquisadores de Institutos de Pesquisa da área ambiental $(2,7 \%)$ e outros profissionais de diversificadas atuações profissionais $(5,8 \%)$.

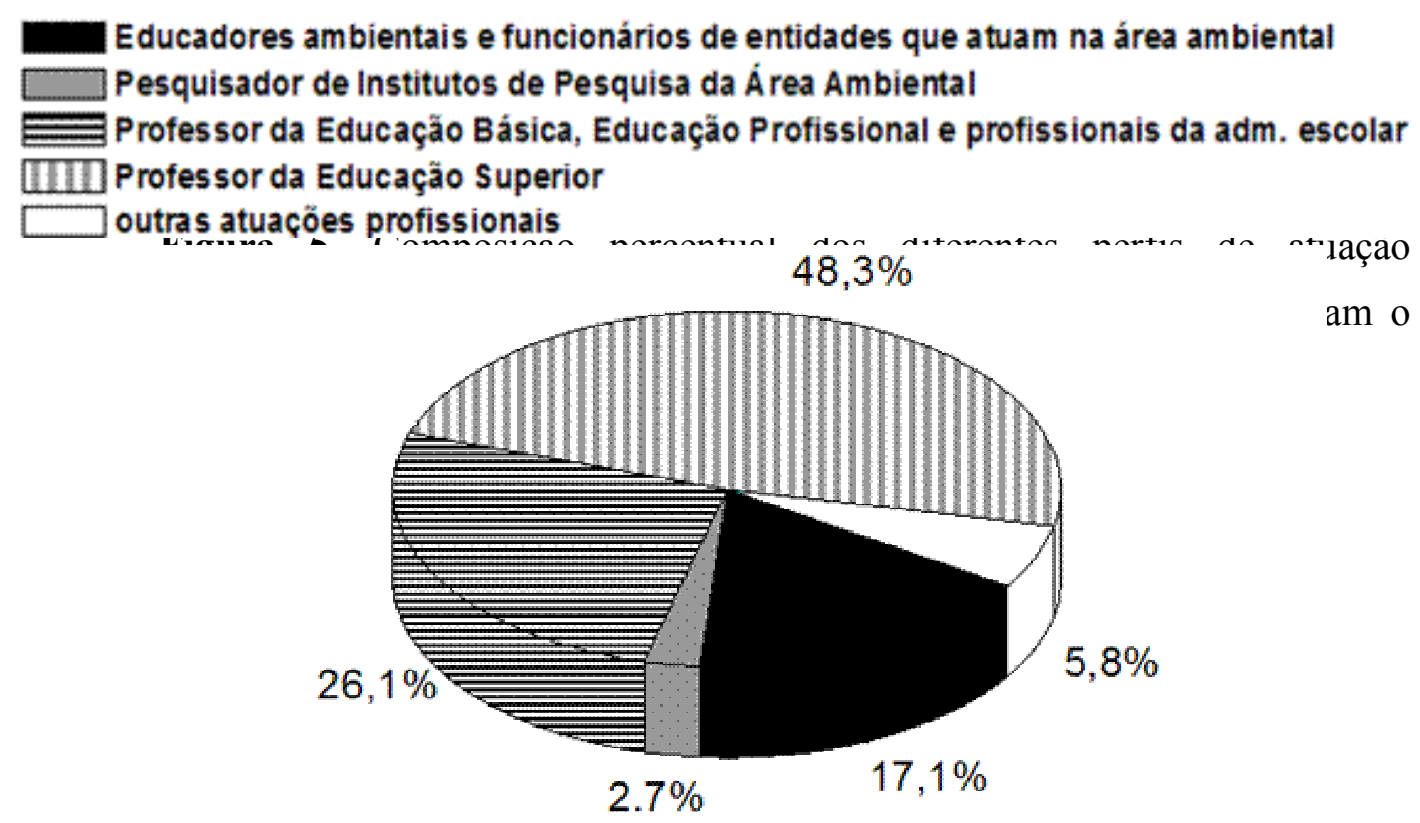


b. Caracterização dos temas dos trabalhos e suas relações com os pesquisadores e suas instituições de origem

1. Os temas dos trabalhos apresentados no evento e sua freqüência:

A partir da leitura e análise dos resumos impressos no Caderno de Resumos do I EPEA, foram reconhecidos os principais temas que foram tratados durante o evento. Inicialmente, eles foram divididos em dois grupos: o primeiro representado por 2 relatos de experiências pedagógicas e outro grande grupo representado por 76 trabalhos que podem ser categorizados como ensaios teóricos ou relatos de pesquisa.

Os 78 trabalhos analisados foram classificados de acordo com os temas desenvolvidos, podendo um mesmo trabalho figurar em mais de um tema. As classificações foram realizadas mediante a análise dos resumos e das palavras-chave indicadas pelos autores. Quatro trabalhos ficaram sem classificação pelo fato de as informações presentes nos resumos serem insuficientes para um agrupamento em qualquer um dos temas. A Tabela 1, a seguir, mostra, em ordem decrescente de freqüência nos trabalhos, os 18 temas identificados:

Tabela 1. Temas identificados nos trabalhos apresentados no I EPEA e a sua freqüência

$\begin{array}{cc}\text { TEMA } & \begin{array}{c}\text { FREQÜÊNCIA DOS TEMAS } \\ \text { NOS TRABALHOS }\end{array} \\ \text { EA no Contexto Escolar } & 23 \\ \text { Formação de Professores } & 11 \\ \text { Avaliação de Programas em EA } & 11 \\ \text { Percepção } & 09 \\ \text { Concepções } & 08 \\ \text { EA em Espaços Não-formais de Ensino } & 04 \\ \text { Representações Sociais } & 04 \\ \text { Construção do Campo da EA } & 04 \\ \text { Movimentos Sociais } & 03 \\ \text { EA e Saúde } & 03\end{array}$


Turismo Ambiental

Política, Meio Ambiente e EA

Formação de Educadores Ambientais

Estudos Culturais

EA e Educação Matemática

Pós-Graduação em EA

Internet e EA

Gestão Ambiental

Com base na Tabela 2, percebe-se uma clara predominância de trabalhos que discutem a educação ambiental no contexto da educação formal, passando por questões relativas aos processos de ensinoaprendizagem, seleção e organização dos conteúdos, discussões curriculares das disciplinas e seus enfoques ambientais.

Em seguida, num segundo bloco, surgem trabalhos que tratam da formação de professores da educação básica. Ou seja, ao mesmo tempo em que se nota uma preocupação das pesquisas com o universo escolar, nota-se também uma preocupação com a formação dos professores que atuam na escola. A formação dos educadores ambientais é tratada como um tema à parte, já que os 11 trabalhos considerados tratam apenas de formação de professores da educação básica atuantes na escola. Outro tema que aparece com freqüência trata da avaliação de programas de educação ambiental com a discussão de instrumentos que forneçam feedback para as propostas de ações educativas.

Um terceiro bloco de temas trata de trabalhos com foco na percepção ambiental em suas diversas categorias e de outros que abordam concepções relacionadas aos temas ambientais. Com freqüência muito mais baixa - quase metade do bloco anterior -, há trabalhos que tratam da educação ambiental em espaços não formais de ensino, tais como, em zoológicos e museus. Foram retirados dessa categoria os trabalhos que versavam sobre a EA em unidades de conservação, pois todos esses trabalhos possuíam o seu foco na 
temática de avaliação de programas em EA. Há ainda trabalhos sobre representações sociais e sobre a construção do campo da EA.

Esses três blocos referem-se aos oito principais temas dos trabalhos analisados. Os demais dez temas de trabalhos, que possuem freqüência abaixo de quatro, representam $18,6 \%$ do total de temas.

Esses demais trabalhos, com freqüência abaixo de 4, referemse a temas variados: Movimentos sociais; EA e Saúde; Turismo Ambiental; Política, Meio Ambiente e EA; Formação de Educadores Ambientais; Estudos Culturais; EA e Educação Matemática; PósGraduação em EA e Internet e EA. Cabe, ainda, um destaque para os temas de Turismo Ambiental e de Gestão Ambiental, que não abordaram questões relativas à Educação Ambiental.

2. Os autores e suas instituições de origem e suas relações com os temas dos trabalhos.

$\mathrm{Na}$ Tabela 2, foram identificadas as instituições de origem dos pesquisadores que apresentaram trabalhos no evento e o número de autorias. Verifica-se que das 38 instituições presentes, há um predomínio de instituições universitárias $(76 \%)$ em relação às não universitárias (24\%). Dentre as universidades, verifica-se um predomínio das públicas $(62 \%)$ em relação às privadas $(28 \%)$. As universidades federais compõem a parcela mais representativa dentre as públicas, perfazendo um total de 11 instituições, seguidas de 6 universidades estaduais e de apenas 1 instituição universitária municipal. Dentre as não universitárias, verifica-se um predomínio de órgãos governamentais (6 instituições), seguidos de 3 organizações não governamentais .

Tabela 2. Número de autorias por instituição 
Universidade Estadual Paulista - UNESP/Rio Claro/SP 23

$\begin{array}{ll}\text { Universidade Estadual Paulista - UNESP/Botucatu/SP } & 10\end{array}$

Universidade Estadual Paulista - UNESP/Bauru/SP 3

Universidade Estadual Paulista - UNESP/Araraquara/SP 1

Universidade Estadual Paulista - UNESP/Guaratinguetá/SP 1

Universidade Estadual Paulista - UNESP/Jaboticabal/SP 1

Universidade Estadual Paulista - UNESP/Ilha Solteira/SP 1

Universidade Federal de São Carlos - UFSCar/São Carlos/SP 20

Universidade de São Paulo - USP/São Paulo/SP 11

Universidade de São Paulo - USP/São Carlos/SP 5

Universidade de São Paulo - USP/Ribeirão Preto/SP 1

Universidade de São Paulo - USP/Piracicaba/SP 2

Universidade Estadual de Campinas- UNICAMP/Campinas/SP 13

Universidade Metodista de Piracicaba- UNIMEP/Piracicaba/SP 1

Instituto Agronômico de Campinas- IAC/Campinas/SP 1

Instituto Florestal da S.M.A. - São Paulo/SP 3

Instituto Pau-Brasil (ONG) - São Paulo/SP 1

Universidade Federal de Santa Maria -UFSM/Santa Maria/SC 1

Universidade do Sagrado Coração - USC/Bauru/SP 1

Universidade Regional de Blumenal - FURB/Blumenau/SC 8

Fundação Educacional São José - SP 1

Faculdade de Turismo $\underline{\text { Santos }}$ Dumont - $\underline{\text { FACTURSD/Santos }} 1$

Universidade Estadual do Rio de Janeiro- UERJ/Rio de Janeiro/RJ 2

Universidade Estadual de Feira de Santana- $\underline{\text { UEFS/Feira de } 1}$ Santana/BA Universidade Federal do Rio Grande do Sul- UFRGS/Rio Grande do
Sul/RS

Universidade Federal do Rio de Janeiro- UFRJ/Rio de Janeiro/RJ 2

Pontifícia Universidade Católica de São Paulo - PUC-SP/São
Paulo/SP

Universidade Federal de Santa Catarina - UFSC/Florianópolis/SC 3

Faculdade Interlagos de Educação e Cultura - FINTEC/São Paulo/SP 2 
Universidade Estadual do Ceará- UEC/ Fortaleza/CE

Parque Zoológico Municipal de Sorocaba - Sorocaba/SP 2

Universidade do Vale do Itajaí - UNIVALI/Itajaí/SC 5

Centro de Referência em Informação Ambiental (ONG) - CRIA/São
6

Paulo/SP

Universidade Federal do Mato Grosso do Sul - UFMS/Campo 1 Grande/MS

Universidade Estácio de Sá - UNESA/Rio de Janeiro/RJ 1

Prefeitura Municipa de Rio Claro - PM-Rio Claro/SP 1

Instituto de Saúde da Secretaria de Saúde de São Paulo - São
Paulo/SP

Universidade Estadual da Paraíba - UEPB/Campina Grande/PB 1

E. E. F. Nossa Senhora de Lurdes (Escola básica) - João Pessoa/PB 1

Universidade Federal do Rio Grande do Norte - UFRN/Natal/RN 2

Verdejar Ambiental (ONG) - São Paulo/SP 1

Universidade Federal de Uberlândia - UFU/Uberlândia/MG 3

Universidade Estadual de Ponta Grossa - UEPG/Ponta Grossa/PR 1

Faculdades Padre Anchieta - Jundiaí/SP 1

Faculdades Integradas de Guarulhos - FIG/Guarulhos/SP 1

Universidade Federal do Espírito Santo - UFES/Vitória/ES 1

Universidade Federal do Mato Grosso - UFMT/Cuiabá/MT 5

Universidade de Taubaté - UNITAU/Taubaté/SP 1

* Os campi relativos a cada uma das instituições foram discriminados separadamente.

** Foram computadas 3 autorias a mais devido 3 autores declararem pertencer a duas diferentes instituições.

Nota-se que a maior parte das autorias dos trabalhos é proveniente das universidades públicas estaduais paulistas, sendo 40 da UNESP, 20 da UFSCar e 19 da USP. Da UNESP, o campus de Rio Claro é o mais representado. É importante salientar que as três instituições organizadoras do evento são as mais representadas.

A Tabela 3 apresenta a relação entre os oito principais temas de trabalho apresentados no evento, o número de autorias e suas respectivas instituições de pesquisa. 
Tabela 3. Distribuição da quantidade de autorias por instituição em relação aos principais temas de trabalho.

\begin{tabular}{|c|c|c|c|c|c|c|c|c|}
\hline \multirow{2}{*}{\begin{tabular}{l|l} 
INSTITUIÇÃO DE ORIGEM DOS \\
AUTORES DOS TRABALHOS *
\end{tabular}} & \multicolumn{8}{|c|}{ PRINCIPAIS TEMAS** } \\
\hline & 1 & 2 & 3 & 4 & 5 & 6 & 7 & 8 \\
\hline $\begin{array}{l}\text { Universidade Estadual Paulista - UNESP/Rio } \\
\text { Claro/SP }\end{array}$ & 10 & & 02 & 01 & 06 & 02 & & \\
\hline $\begin{array}{ll}\text { Universidade } \quad \text { Estadual } & \text { Paulista } \\
\text { UNESP/Botucatu/SP } & \end{array}$ & 03 & & & & 03 & & 02 & \\
\hline Universidade Estadual Paulista - UNESP/Bauru/SP & 02 & 01 & 02 & & & & & \\
\hline $\begin{array}{lcc}\text { Universidade } & \text { Estadual } & \text { Paulista } \\
\text { UNESP/Araraquara/SP } & \end{array}$ & 01 & & & & & & & \\
\hline $\begin{array}{lcc}\text { Universidade } & \text { Estadual } & \text { Paulista } \\
\text { UNESP/Guaratinguetá/SP } & \end{array}$ & & & & & 01 & & & \\
\hline $\begin{array}{lll}\text { Universidade } & \text { Estadual } & \text { Paulista } \\
\text { UNESP/Jaboticabal/SP } & \\
\end{array}$ & & 01 & & & & & & \\
\hline $\begin{array}{llll}\text { Universidade } & \text { Estadual Paulista } & \text { - UNESP/Ilha } \\
\text { Solteira/SP } & & & \\
\end{array}$ & 04 & 06 & 04 & 04 & 04 & & 01 & \\
\hline $\begin{array}{l}\text { Universidade Federal de São Carlos - UFSCar/São } \\
\text { Carlos/SP }\end{array}$ & 02 & 03 & 02 & & 02 & 02 & & \\
\hline Universidade de São Paulo - USP/São Paulo/SP & 01 & & 02 & 01 & & & & \\
\hline Universidade de São Paulo - USP/São Carlos/SP & & & & & & & & 01 \\
\hline Universidade de São Paulo - USP/Ribeirão Preto/SP & & & & 01 & & & & \\
\hline Universidade de São Paulo - USP/Piracicaba/SP & 06 & & & & & & & \\
\hline $\begin{array}{lccc}\text { Universidade } & \text { Estadual } & \text { de } & \text { Campinas- } \\
\text { UNICAMP/Campinas/SP } & & \\
\end{array}$ & 02 & & & & & & & \\
\hline $\begin{array}{llll}\text { Universidade } \quad \text { Metodista } & \text { de } & \text { Piracicaba- } \\
\text { UNIMEP/Piracicaba/SP } & & \\
\end{array}$ & 01 & & & & & & & \\
\hline $\begin{array}{lll}\text { Instituto Agronômico } & \text { de } & \text { Campinas } \\
\text { IAC/Campinas/SP } & & \\
\end{array}$ & & & 03 & & & & & \\
\hline Instituto Florestal da S.M.A. - São Paulo/SP & & & & & & 01 & & \\
\hline Instituto Pau-Brasil (ONG) - São Paulo/SP & & & & & & & 01 & \\
\hline $\begin{array}{l}\text { Universidade Federal de Santa Maria -UFSM/Santa } \\
\text { Maria/SC }\end{array}$ & 01 & & & & & & & \\
\hline Universidade do Sagrado Coração - USC/Bauru/SP & 02 & & & 03 & & & & 01 \\
\hline $\begin{array}{lllll}\text { Universidade } & \text { Regional } & \text { de } & \text { Blumenal } & - \\
\text { FURB/Blumenau/SC } & & & \\
\end{array}$ & 01 & & & & 01 & & & \\
\hline Fundação Educacional São José - SP & 01 & & & & 01 & & & \\
\hline $\begin{array}{lcccc}\text { Faculdade } & \text { de } & \text { Turismo } & \text { Santos } & \text { Dumont } \\
\text { FACTURSD/Santos Dumont/MG } & & \\
\end{array}$ & & & 01 & & & & & \\
\hline $\begin{array}{l}\text { Universidade Estadual do Rio de Janeiro- UERJ/Rio } \\
\text { de Janeiro/RJ }\end{array}$ & & & 01 & & & & & \\
\hline $\begin{array}{l}\text { Universidade Estadual de Feira de Santana- } \\
\text { UEFS/Feira de Santana/BA }\end{array}$ & & & 01 & & & & & \\
\hline Universidade Federal do Rio Grande do Sul- & & & & & & & & \\
\hline
\end{tabular}




\begin{tabular}{|c|c|c|c|c|c|c|c|c|}
\hline \multirow{2}{*}{$\begin{array}{l}\text { UFRGS/Rio Grande do Sul/RS } \\
\text { Universidade Federal do Rio de Janeiro- UFRJ/Rio } \\
\text { de Janeiro/RJ }\end{array}$} & & & & & & & & \\
\hline & & & & 01 & & & & \\
\hline $\begin{array}{l}\text { Pontifícia Universidade Católica de São Paulo - } \\
\text { PUC-SP/São Paulo/SP }\end{array}$ & & & & & & & 01 & \\
\hline $\begin{array}{lrllll}\text { Universidade } & \text { Federal de } & \text { Santa } & \text { Catarina } & - \\
\text { UFSC/Florianópolis/SC } & & & & \\
\end{array}$ & & & 02 & & & 02 & & \\
\hline $\begin{array}{l}\text { Faculdade Interlagos de Educação e Cultura - } \\
\text { FINTEC/São Paulo/SP }\end{array}$ & 03 & 03 & & 02 & & & & \\
\hline $\begin{array}{lllll}\text { Universidade } & \text { Estadual } & \text { do } & \text { Ceará- } & \text { UEC/ } \\
\text { Fortaleza/CE } & & & & \end{array}$ & & & & & & & & 06 \\
\hline $\begin{array}{lllll}\text { Parque Zoológico Municipal de Sorocaba } & - \\
\text { Sorocaba/SP }\end{array}$ & & & & 01 & & & & \\
\hline Universidade do Vale do Itajaí - UNIVALI/Itajaí/SC & & & & & & & & 01 \\
\hline $\begin{array}{l}\text { Centro de Referência em Informação Ambiental } \\
\text { (ONG) - CRIA/São Paulo/SP }\end{array}$ & & & & & & & 01 & \\
\hline $\begin{array}{l}\text { Universidade Federal do Mato Grosso do Sul - } \\
\text { UFMS/Campo Grande/MS }\end{array}$ & & & & & & & 01 & \\
\hline $\begin{array}{l}\text { Universidade Estácio de Sá - UNESA/Rio de } \\
\text { Janeiro/RJ }\end{array}$ & & 02 & & & & & & \\
\hline Prefeitura Municipal de Rio Claro - PM-Rio Claro/SP & & & & & 03 & & & \\
\hline $\begin{array}{l}\text { Instituto de Saúde da Secretaria de Saúde de São } \\
\text { Paulo - São Paulo/SP }\end{array}$ & 01 & & & 01 & & & & \\
\hline $\begin{array}{l}\text { Universidade Estadual da Paraíba - UEPB/Campina } \\
\text { Grande/PB }\end{array}$ & & 01 & & & & & & \\
\hline $\begin{array}{l}\text { E. E. F. Nossa Senhora de Lurdes (Escola básica)- } \\
\text { João Pessoa/PB }\end{array}$ & 01 & & & & & & & \\
\hline $\begin{array}{l}\text { Universidade Federal do Rio Grande do Norte - } \\
\text { UFRN/Natal/RN }\end{array}$ & & 01 & & & & & & \\
\hline Verdejar Ambiental (ONG) - São Paulo/SP & & 01 & & 03 & & & & \\
\hline $\begin{array}{l}\text { Universidade Federal de } \quad \text { Uberlândia } \\
\text { UFU/Uberlândia/MG }\end{array}$ & & 01 & & & & & & \\
\hline
\end{tabular}

* Os campi relativos a cada uma das Instituições foram discriminados separadamente.

** 1 - EA no contexto escolar. 2 - Formação de professores, 3 - Avaliação de Programas em EA, 4 - Percepção, 5 -Concepções, 6 - EA em espaços não formais de ensino, 7 - Representações Sociais, 8 - Construção do Campo da EA.

Observa-se que as autorias de trabalhos com temas relacionados à prática escolar e ao estudo das concepções estão concentradas na UNESP, principalmente no campus de Rio Claro. A UFSCar figura em quase todos os temas com uma média de 4 autores por tema. Nota-se uma predominância de autorias no tema Formação de Professores. É importante salientar que esses temas coincidem com as linhas de pesquisa desenvolvidas nos Programas de Pós-Graduação em Educação dessas instituições. 
Temas como a educação ambiental em espaços não formais têm como autorias pessoas provenientes de ONGs ou outros órgãos públicos que não a universidade.

\section{c. Delineamento do perfil inicial do pesquisador em EA}

Quando se pensou em criar um fórum para discutir a pesquisa em educação ambiental no país, não se sabia ao certo qual a natureza dos trabalhos apresentados ou qual seria o perfil dos seus participantes. Enfim, que tipo de produção científica surgiria? Que comunidade científica se organizaria em torno dessa produção? Sabiase que havia um potencial "represado" de uma certa produção científica nessa área, mas que ainda aparecia de forma difusa e dispersa nos vários eventos, realizados a partir das mais diferentes áreas do conhecimento. Foi apostando nessa perspectiva que se realizou o primeiro evento que, surpreendentemente, trouxe a presença de um público significativo de 368 participantes.

Quem somos nós? Esta é a primeira questão que surge quando se busca compreender a identidade de uma comunidade vindoura e, quem sabe, de um campo novo que se constitui. Identificar os sujeitos de uma comunidade de uma área emergente e acompanhar a sua trajetória são importantes pontos de partida para entender a própria evolução dessa área.

Quem é este pesquisador em EA? Que conexões podem ser estabelecidas entre o pesquisador em EA e o educador ambiental, já que a pesquisa em questão refere-se ao campo da EA? Estudos anteriores sobre o educador ambiental (Kawasaki, 2001 e Carvalho, 2001) foram referenciais iniciais e contrapontos importantes para a análise dessas questões.

A partir da análise crítica da sua própria trajetória de formação, enquanto educador ambiental, Kawasaki (2001) constata que essa formação não se deu unicamente no contexto escolar ${ }^{4}$, ou mesmo em

4

Embora a educação ambiental (EA) seja um componente essencial e permanente da educação nacional, devendo estar presente, de forma articulada, em todos os níveis e modalidades do processo educativo (Lei N 9.795, de 27/04/99), não 
um contexto único, mas em diferentes espaços institucionais e sociais. Realizou-se na confluência de uma multiplicidade de experiências e consolidou-se, sobretudo, na sua atuação profissional, política e cidadã, como professora e militante na área ambiental. Significa dizer que, enquanto educadora ambiental, trilhou múltiplos caminhos, ou seja, percorreu uma trajetória que não foi linear. E nessa trajetória desempenhou diferentes papéis - gestora, educadora, professora, política e cidadã -, o que a conduziu a uma nova constatação: a de que o educador ambiental possui um perfil que não é único, podendo-se até dizer que há diferentes perfis de educador ambiental, em razão das diferentes trajetórias que percorre.

Carvalho (2001), ao apontar a EA enquanto profissão militante e parte de um projeto político emancipatório, traduz o significado desse perfil (ou perfis) do educador ambiental:

O papel do educador ambiental está atravessado pelas marcas do agir político. As condições do percurso da própria educação ambiental apontam para a sobreposição de marcas de um movimento social e as de uma esfera educativa epistemologicamente organizada. Neste contexto, a identidade do educador ambiental está longe de ser uma identidade totalizante. Múltiplos os caminhos, as vias de acesso e os ritos de entrada pelos quais um sujeito pode se tornar um educador ambiental. Nomear-se educador ambiental aparece ora como adesão a um ideário, ora como sinônimo de um ser ideal ainda não alcançado, ora opção de profissionalização, ora como signo descritor de uma prática educativa ambientalizada, combinando em diferentes gradações as vias da militância e da profissionalização num perfil profissional-militante. (CARVALHO, 2001, p.54)

há no Brasil uma formação específica escolar voltada para essa formação. Mesmo porque isso seria um contra-senso, dado que na própria Lei, a EA deve fazer parte de um processo educativo mais amplo, ou seja, desenvolver-se por meio das várias instituições sociais e da sociedade como um todo, já que busca uma compreensão integrada do meio ambiente em suas múltiplas e complexas relações. 
Prováveis explicações para essa trajetória não linear e perfis variados do educador ambiental, podem ser encontradas nas próprias características do campo da EA, conforme considerações feitas por essa mesma autora. Para Carvalho (2001), o campo da EA surge da confluência do campo ambiental e do campo educativo com suas tradições pedagógicas, embora, pela experiência brasileira, a EA pareça ser um fenômeno cuja gênese e desenvolvimento estariam mais ligados aos movimentos ecológicos e ao debate ambientalista do que propriamente ao campo educacional e à teoria da educação. Neste sentido, afirma ainda que a EA é herdeira direta do movimento ecológico e do debate internacional sobre meio ambiente, já que surge, primeiramente, ligada às políticas ambientais e aos órgãos do meio ambiente enquanto ação educativa não formal e apenas posteriormente a EA será internalizada pelas políticas educacionais e os órgãos de educação como ação educativa formal, na forma de tema curricular transversal no contexto escolar.

Que correlações é possível estabelecer entre esse perfil (ou perfis) do educador ambiental e o pesquisador em EA? Qual é o perfil (ou perfis) do pesquisador em EA que é possível identificar a partir deste estudo?

A partir dos dados dos sujeitos desta pesquisa, alguns delineamentos a esse respeito podem ser feitos. O que se verifica é que não há um perfil único de pesquisador em EA, e sim vários, porém, apenas dois perfis foram destacados.

Há um perfil predominante, que é aquele pesquisador cuja origem geográfica é a Região Sudeste e, mais precisamente, o Estado de São Paulo. Este é, ainda, do sexo feminino, na faixa etária entre 20 e 30 anos, formado em Ciências Biológicas, ativo no mercado de trabalho e atuando como profissional da educação, principalmente como professor no ensino superior e na educação básica.

Há também um perfil significativo, que é aquele pesquisador cuja origem geográfica sai desta área de influência do evento, indo para a Região Sul e, mais, abrangendo dezenove Estados e todas as regiões brasileiras. Neste perfil, o pesquisador vem das áreas das Ciências da Natureza (que não as Ciências Biológicas), das áreas de 
Humanidades e, sobretudo, de Outras Áreas, cujo grau de dispersão é bastante elevado. Este, ainda, atua profissionalmente em instituições não universitárias, privadas ou em órgãos governamentais e não governamentais . Nos dois perfis, é possível identificar um sujeito jovem, considerando-se que a comunidade é de pesquisadores de um campo científico.

Similarmente aos resultados encontrados nos estudos anteriores sobre o perfil do educador ambiental, foi possível identificar perfis variados de pesquisador em EA, resultantes de uma trajetória não linear, destacando-se, mais uma vez, a multiplicidade e a diversidade de sujeitos e contextos de formação e atuação. Há, no entanto, um viés claro nessa multiplicidade, pois para $46 \%$ desses pesquisadores, essas trajetórias variadas acabam por desembocar num lugar comum: os programas de Pós-Graduação, aos quais se vinculam os pesquisadores. Programas esses de instituições universitárias, públicas e, predominantemente, da região Sudeste, de onde resultou a maior parte dos trabalhos de pesquisa enviados ao I EPEA. Essa tendência fica bastante clara ao identificar-se que as temáticas de pesquisa mais presentes no evento relacionam-se às linhas de pesquisa de Programas de Pós-Graduação dessas universidades públicas, onde se concentram os pesquisadores que compõem as comissões organizadora e científica do evento.

Em suma, não há como negar a diversidade desses sujeitos e de suas trajetórias; contudo, é possível reconhecer uma certa identidade nesta comunidade que orbita em torno de algo que lhe é comum: a pesquisa científica e a academia.

\section{d. Elementos para a constituição do campo de pesquisa em EA}

A partir do perfil do pesquisador em EA, é possível afirmar que há um campo de pesquisa em EA? Se sim, que aspectos da constituição de um campo de pesquisa em EA estão presentes?

Para essas questões, buscou-se, inicialmente, identificar o que, para Bourdieu (1983), representam os elementos básicos da constituição de um campo. Há objetos de disputa e pessoas prontas 
para disputar o jogo, dotadas de habitus que impliquem o conhecimento e o reconhecimento das leis desse jogo? Há estratégias de conservação (ou "ortodoxia") e de subversão (ou "heterodoxia") do campo, em torno dos objetos de disputa? Há um espaço onde as pessoas que estão engajadas nesse campo têm um certo número de interesses fundamentais em comum, o que resulta na cumplicidade objetiva subjacente a todos os antagonismos?

Em seguida, para a identificação de alguns dos aspectos do campo de pesquisa em EA, foram utilizados os estudos de Garcia $^{5}$ (1996), de Carvalho ${ }^{6}$ (2001) e de Almeida ${ }^{7}$ (2006), que exploraram as

5

Em Garcia (1996), o conceito de campo de Bourdieu refere-se aos diferentes espaços da vida social ou da prática social, que possuem uma estrutura própria e relativamente autônoma com relação a outros espaços ou campos sociais. Esses campos organizam-se em torno de objetivos e práticas específicas e apresentam apesar das homologias que os unem - uma lógica própria de funcionamento que estrutura as relações entre os agentes no interior de cada um deles. Para Bourdieu, existem homologias estruturais e funcionais, mesmo considerando-se que os fenômenos, em cada um desses campos particulares, revistam-se de formas específicas e irredutíveis umas às outras. A teoria geral dos campos é o método analítico que busca uma lógica de funcionamento comum a diferentes campos particularizados. Ao definir um campo, indica que os agentes que o constituem são portadores de um determinado habitus adaptado às exigências e necessidades do campo em questão

6 Em Carvalho (2001), a construção de uma prática educativa denominada educação ambiental e a identidade profissional de um educador ambiental a ela associada são desdobramentos que podem ser entendidos como parte dos movimentos de legitimação de um campo ambiental, tanto em termos internacionais quanto no caso brasileiro. Neste sentido, a EA corrobora para a formação do campo na medida que se constitui uma categoria entre os novos especialistas em meio ambiente. $\mathrm{O}$ educador ambiental é um dos novos profissionais que ganham destaque no campo ambiental pelo seu papel pedagógico e sua missão de formação de novos sujeitos ambientalizados. Evidentemente, ao constituir-se enquanto prática educativa, a EA também se filia ao campo da educação propriamente dito. E da confluência entre o campo ambiental e o campo educativo com suas tradições pedagógicas que vão surgir as orientações específicas dentro da EA

Para Almeida (2006), a construção desse conceito enfatiza a idéia de um espaço de produção simbólica (artística, científica, literária, etc.) como espaço social de relações objetivas. O campo é definido como um espaço de lutas onde há objetos de disputa, interesses específicos e pessoas prontas para disputar o jogo, dotadas de habitus que impliquem o conhecimento e o reconhecimento das leis imanentes desse jogo, dos objetos de disputas, etc. O campo também é um espaço onde as pessoas que estão engajadas nesse campo têm um certo número de interesses fundamentais em comum, o que resulta na cumplicidade objetiva subjacente a todos os antagonismos. Há um interesse comum das pessoas engajadas num campo, que supera os antagonismos e as faz cúmplices no que se refere a tudo aquilo que está ligado à própria existência do campo, o que as une principalmente em relação a fatores que 
implicações da aplicação das categorias bourdieunianas na análise do desenvolvimento de determinados campos ou disciplinas acadêmicas e científicas.

De Garcia (1996), foi possível identificar aspectos da estrutura e funcionamento dos campos científico, universitário francês ${ }^{8}$ e das Ciências Sociais ${ }^{9}$. De Carvalho (2001), a partir de um resgate histórico dos movimentos sociais e suas relações com os movimentos ambientalistas e com a EA, foi possível retomar alguns marcos da formação e legitimação do campo ambiental no Brasil e aspectos da constituição do campo da EA. Almeida (2006), ao pensar a constituição científico-acadêmica das Ciências da Informação e identificar os profissionais e os pesquisadores da informação como mediadores ${ }^{10}$, trouxe uma noção de sujeitos mediadores, que subsidiou a compreensão sobre os sujeitos do campo de pesquisa em EA. Este estudo trouxe, ainda, a noção de redes de cooperação de Becker (1977), que permitiu uma análise do funcionamento do campo, para além dos objetos de disputa de Bourdieu.

Conforme salientado anteriormente, há uma convergência dos pesquisadores em EA em torno de algo que lhes é comum: a pesquisa científica e a academia. De fato, é para o campo científico que confluem esses sujeitos múltiplos de trajetórias variadas. Os dados sobre a origem institucional dos membros das comissões organizadora e científica do evento e a origem institucional dos autores de trabalhos apresentados no evento apontam a presença predominante de

\footnotetext{
atuam contra a autonomia do mesmo. Ocorre, portanto, um acordo entre os antagonistas a respeito do que merece ser disputado. Por diferentes vias, a Academia (no plano intelectual) e as associações e conselhos de classe cumprem a função de zelar pela "ortodoxia" do campo, estabelecendo seus limites e sancionando e/ou atribuindo a "legitimidade cultural" a seus membros. Nesse sentido, torna-se difícil situar exatamente o início da constituição de um campo específico.

9 Realizada pelo próprio Bourdieu na obra Homo Academicus.

$9 \quad$ Por Monique de Saint Martin (1988)

$1 \quad{ }^{0} \mathrm{Na}$ opinião do autor, os profissionais e os pesquisadores da informação se encaixam nessa categoria, a dos trabalhos que se voltam para as necessidades de outros seres humanos; são, antes de mais nada, mediadores, e é daí que deve ser pensada sua identidade profissional, seu papel social e a reflexão intelectual sobre as questões da área.
} 
instituições universitárias públicas, estaduais ou federais e seus respectivos Programas de Pós-Graduação em Educação. Acrescente-se ainda o fato de que as oito temáticas de pesquisa mais freqüentes neste evento referem-se às linhas de pesquisa desses Programas de PósGraduação. Essa tendência situa claramente a autoridade científica deste evento nessas instituições universitárias, sobretudo nesses Programas, que acabam estabelecendo os parâmetros para a avaliação das pesquisas científicas. Tal perspectiva não apresenta qualquer novidade, dado que se trata de um evento de natureza científica e organizado pela academia universitária.

Todavia, é importante lembrar que, para além dessa tendência predominante, há uma dispersão acadêmico-institucional desses pesquisadores e uma multiplicidade de temáticas de pesquisa, trazendo perspectivas e tendências outras da pesquisa em EA, como aquelas que são científicas mas não necessariamente acadêmicas. Nesse contexto, surgem novos sujeitos de pesquisa e novos aportes teóricos. Mesmo para esses novos sujeitos de pesquisa, há um ponto de convergência a se considerar: seus trabalhos passaram pelo mesmo crivo, o da comissão científica, que tinha como missão selecionar apenas aqueles trabalhos que considerava ser uma pesquisa científica. "O que é uma pesquisa científica em EA?", eis uma questão que pode se configurar num importante objeto de disputa. Há um limite claro entre o que é e o que não é uma pesquisa científica nesse campo? Há regras que norteiam essa decisão? Essas regras estão explicitadas? Há conflito ou consenso em torno delas? A quem cabe a decisão sobre tais questões? O que se pode dizer, a partir deste evento, é que as respostas para essas questões são objetos de disputa entre os sujeitos pesquisadores, pois é em torno delas, e numa perspectiva de construção dos referenciais científicos, que se inicia e se constitui aquilo que se chama de um campo de pesquisa em EA.

Em suma, percebe-se que a autoridade científica não está dada; ao contrário, vem sendo construída, e não apenas pelos grupos que possuem a primazia desse bem simbólico, mas também pelos grupos minoritários, que ao trazerem uma diversidade significativa, 
estabelecem um embate vigoroso e produtivo em torno daquilo que é fundamental para um campo: a construção de sua própria identidade ${ }^{11}$. Garcia (1996), ao discutir a estrutura e funcionamento do campo científico, coloca um paradoxo: o avanço da ciência e do conhecimento científico é o resultado de lutas entre posições e agentes que disputam espécie específica de capital simbólico - a autoridade e/ou legitimidade científica.

Avanzi (2004), em seu artigo de avaliação do II EPEA, aponta a prevalência de pesquisadores de universidades públicas como principais autores das pesquisas apresentadas no EPEA e a ausência de pesquisadores de instituições não universitárias, das ONGs e dos movimentos sociais, questionando o seguinte: "Estaria a pesquisa restrita ao meio acadêmico?" A partir disso, aponta duas necessidades: a de explicitar os critérios de avaliação dos trabalhos, trazendo uma horizontalidade entre quem desenvolve as pesquisas e quem as seleciona, e a de ampliar a divulgação do evento, para trazer outras instituições de naturezas diversas, alcançando um público maior e possibilitando para além das universidades públicas estaduais paulistas a criação de um espaço a ser ocupado por outros atores da pesquisa em EA. Neste episódio, há claramente a entrada de novos sujeitos de pesquisa, oriundos de outros campos que não o exclusivamente acadêmico, no caso, sujeitos do campo ambiental, que questionam e disputam a autoridade científica. Tais questionamentos, que expressam tensões no interior do campo, encontram algumas explicações:

Desse modo, qualquer campo simbólico (incluído aí o campo científico) combinaria um conjunto de leis próprias (imposição dos limites para as ações), a busca pela "distinção" (o reconhecimento social e simbólico dos "pares") e a "legitimidade cultural" (o monopólio da manipulação legítima de uma classe determinada de bens simbólicos). O campo é um espaço de disputa, principalmente entre o pólo do novo, dos indivíduos que reivindicam o direito de

\footnotetext{
1 Identidade do campo entendida aqui como suas questões e suas teorias,
suas fronteiras e suas zonas de intersecção com outras áreas, sua institucionalização e formação de quadros.
} 
entrada nesse espaço, e o pólo dominante, que tenta defender o monopólio e excluir a concorrência (Almeida, 2006, p.4).

Ao mesmo tempo em que se estabelecem tensões em torno desses objetos de disputa, há movimentos no interior do campo que buscam acordos entre as partes, já que há um interesse comum das pessoas engajadas num campo que supera os antagonismos e as faz cúmplices no que se refere a tudo aquilo que está ligado à própria existência do campo (Almeida, 2006). Em relação a este evento, a busca de um acordo expressa-se, inicialmente, na disposição desses sujeitos em participar de um jogo cujas regras estão no campo científico. Embora haja um embate entre os campos acadêmico, ambiental e até mesmo pedagógico, quando se verifica, neste evento, a presença significativa de pesquisas científicas que envolvem experiências pedagógicas, há um reconhecimento, ainda que de forma preliminar e tácita, de que a autoridade científica encontra-se no campo da ciência.

De forma geral, todos os campos se estruturam com base nas relações de aliança e/ou disputa em torno dos seus objetos de disputa. É nesse contexto que surgem as estratégias de conservação e de subversão entre os grupos que compõem um campo específico. As tentativas dos grupos pesquisadores predominantes deste evento, na busca de uma autonomização do campo, ou seja, na busca de uma organização interna que dê identidade e especificidade ao mesmo, representam as estratégias de conservação. As tentativas dos grupos minoritários de introduzir sujeitos e referenciais novos, questionando a primazia dos grupos dominantes e sua hegemonia, representam as estratégias de subversão de um campo. Tais movimentos fazem parte de todo processo de constituição de um campo. Um campo é tanto mais autônomo quanto maior o seu poder para definir as normas que orientam a sua produção, as condutas de seus membros, os critérios de avaliação de seus produtos e o poder de retraduzir todas as determinações externas de acordo com seus princípios próprios de funcionamento (Bourdieu, 1983). Significa dizer que, quanto mais o campo conquista a sua autonomia, maior a sua normatização interna, 
ou seja, mais acaba se fechando em si mesmo. Daí a importância dos grupos subversivos, que ao questionarem a autoridade dada, garantem a diversidade e a abertura para novas contribuições.

Em suma, a partir destas considerações, é possível afirmar que há um campo de pesquisa em EA e que este resulta da confluência de diferentes campos: o ambiental, o educacional e o científico. Há tensões entre eles em torno de objetos de disputa, mas essas promovem embates produtivos e um movimento dinâmico no interior de um campo científico, no qual seus sujeitos se reconhecem e se identificam.

Para compreender melhor os sujeitos deste campo, o presente estudo apropria-se da noção de sujeitos mediadores de Almeida (2006). Ao referir-se à crise de identidade da área das Ciências da Informação, o autor chama a atenção sobre uma disputa "bibliotecário" versus "cientista da informação", que considera pouco produtiva, recolocando como a identidade do profissional dessa área poderia ser pensada:

Pouco produtiva porque existe uma característica comum às diversas atividades do campo da Ciência da Informação: os profissionais da área trabalham todos sob o signo de Hermes, são todos, em alguma medida, mediadores. É claro que, obviamente, existem especificidades, decorrentes das particularidades e necessidades de cada instituição e da divisão do trabalho dentro do campo relembremos a noção de redes de trabalho cooperativo de Becker. Mas todos necessitam, em alguma medida, de competências comunicacionais e culturais para estabelecer o trânsito entre as necessidades dos usuários e os estoques de informação, seja na biblioteca do bairro, seja no banco de dados da Nasa. (ALMEIDA, 2006, p. 11)

Em alguma medida, os pesquisadores em EA são, também, sujeitos mediadores. Em suma, são sujeitos que realizam mediações entre: suas áreas específicas (de formação acadêmica, de atuação profissional e atuação na pesquisa) e a área de EA, produzindo pesquisas científicas que tragam questões e objetivos para o campo de EA, sem a pretensão de abranger a totalidade do mesmo, mas trazendo 
o seu recorte; os próprios pares, promovendo um diálogo entre essas especificidades/recortes e construindo redes de cooperação para uma elaboração coletiva desse campo científico em formação; o que se estabelece, rumo a uma organização interna e autonomização do campo, e o porvir, garantindo a abertura para o novo e para a diversidade de pesquisas e sujeitos de pesquisa; o contexto interno, referente ao campo de pesquisa em EA, e o contexto externo, referente a outros campos, propiciando interfaces produtivas entre os campos e intercâmbio entre as suas comunidades, o que significa assegurar um fluxo contínuo interno-externo.

\section{Considerações Finais}

A partir de dados quantitativos, tomados em seu conjunto e de forma inter-relacionada, pôde-se chegar a dados qualitativos dos participantes e envolvidos no I EPEA. Apesar desta análise se situar em apenas um evento e em sua primeira versão, a análise qualitativa permitiu caracterizar o perfil (ou perfis) inicial (ais) do pesquisador em EA, além de trazer elementos para a discussão sobre a constituição de um campo de pesquisa nesta área. É importante frisar que estes estudos referem-se ao contexto específico de um evento científico na referida área de pesquisa e, por isso, trazem as limitações quanto à sua abrangência e grau de generalidade. Assim, é preciso ampliar esta análise, trazendo outros aspectos, outros sujeitos pesquisadores e outros contextos científicos, bem como acompanhar, de forma mais sistemática, a trajetória de cada um deles, para traçar este perfil (ou perfis). É preciso, ainda, analisar outros EPEAs, para acompanhar a trajetória dos sujeitos e a evolução do campo de pesquisa em questão. As discussões e reflexões apresentadas neste artigo trazem perspectivas e questões para futuros estudos sobre a constituição do campo de pesquisa em EA. 


\section{Referências bibliográficas}

ALMEIDA, Marco Antonio de. Informação, cultura e sociedade - reflexões sobre a ciência da informação a partir das ciências sociais. Ribeirão Preto: Faculdade de Filosofia, Ciências e Letras de Ribeirão Preto, mimeo, 2006.

AVANZI, Maria Rita e SILVA, Rosana Louro Ferreira. Traçando os caminhos da pesquisa em educação ambiental: uma reflexão sobre o II EPEA.Quaestio: Revista de Estudos da Educação, Sorocaba, 1 (1): 123-132, maio 1999.

BECKER, Howard. Arte como ação coletiva. Uma teoria da ação coletiva. Rio de Janeiro: Zahar Editores, 1977. p. 205-222.

BOURDIEU, Pierre. O campo científico. In: ORTIZ, Renato (Org.). Pierre Bourdieu: sociologia. São Paulo: Editora Ática, 1983. p. 122-155.

CARVALHO, Isabel Cristina de Moura. Educação Ambiental e Movimentos Sociais: elementos para uma história política do campo ambiental. Educação: Teoria e Prática, Rio Claro, 9(16/17): 46-56, jan./jun. jul./dez., 2001.

CARVALHO, L.M. et al. (org.). Pesquisas em Educação Ambiental: tendências e perspectivas. In: I ENCONTRO DE PESQUISA EM EDUCAÇÃO AMBIENTAL, 2001. Cadernos de Resumos do I EPEA, Rio Claro: UNESP, 2001.

GARCIA, Maria Manuela Alves. O campo das produções simbólicas e o campo científico em Bourdieu. Cadernos de Pesquisa, São Paulo, 97: 64-72, maio 1996.

KAWASAKI, Clarice Sumi. A trajetória de formação do educador ambiental: reflexões para a constituição do campo da educação ambiental. In: I ENCONTRO DE PESQUISA EM EDUCAÇÃO AMBIENTAL, 2001. Anais do I EPEA, Rio Claro: UNESP, 2001.

TRIVELATO, Silvia Luzia Frateschi. O currículo de ciências e a pesquisa em educação ambiental. Educação: Teoria $e$ Prática, Rio Claro, 9(16/17): 57-61, jan./jun. 